\title{
INHERITANCE MODE OF VIRULANCE IN NECTRIA HAEMATOCOCCA MATTING POPULATION I
}

\author{
Ahmed M. M. A. Kasem \\ Department of Botany \& Microbiology, Faculty of Science, Al-azhar University, Assiut (71524), Egypt.
}

\begin{abstract}
ABESTRACT
The difference in virulence of two standard strains in colonizing seedling hypocotyle and fruit exocarp suggested that multi-locus control of this trait. Whereas, Strain ATCC18099 was unable to infect uninjured cucumber and Zucchini fruits, both strains had high virulence against seedlings. The inheritance mode of this trait was studied by tetrad and random ascospore analysis with ascospores obtained from reciprocal crossings between ATCC18098 and ATCC18099. Segregation of MAT and perithecial color was also examined in both types of ascospore analyses. The results of tetrad analysis indicated 4:4 segregation for the high virulence associated with strain ATCC18098 in each tetrad, suggesting a Mendelian mode of inheritance. In random ascospore analysis, chi-square test supported that progeny with and without high virulence segregated in 1:1 in each cross and linkage analysis showed that such trait segregated independently from either MAT or perithecial color trait.
\end{abstract}

KEY WORDS

Virulence, N. haematococca MPI, reciprocal crossing. Cucurbita sativus, C. pepo, Tetrad analyses.

INTRODUCTION

Fusarium solani f. sp. cucurbitae is a common soil borne important pathogen on cucurbit plants all over the world. Two races of this pathogen have been identified on the basis of tissue specificity. Race 1 infects hypocotyls causing cortical stem rot, and mature fruits causing a dry rot. On the other hand, Race 2, attacks only fruits $[1,2]$. The perfect stage Nectria haematococca Berk. \& Broome, has been described for both races. The $N$. haematococca mating population I (MPI) (anamorph, F. solani f. sp. Cucurbitae race 1) is the causal agent of Fusarium crown and foot rot disease of cucurbits [2]. It prevails all over the world, causing serious damages on the cultivation of cucurbits.

The pathogenicity is a polygenetically controlled character in N. haematococca MPI and 6-12 effective factors control its pathogenicity on hypocotyls of Cucurbita maxima [3]. However, Virulence is a complex character and the genetics controlling it may differ significantly from one pathogen to another and genetic factors controlling host specificity or general virulence include host defense detoxifying agents, avirulence genes, toxins and degrading enzymes [4].

In this sense, cucurbit fruit exhibited variability for overall susceptibility to $N$. haematococca MPI as evidenced by the number of fruit infected, time to sporulation, and extent of infection. Susceptibility did not correlate with taxonomic classification, while summer squash and zucchini were highly susceptible; acorn squash and pumpkin were less susceptible. Also, thickness of rind did not correlate with the susceptibility, as muskmelon was one of the most susceptible, and cucumber one of the least [4].

While some fungi cannot be subjected to crossing experiments, $N$. haematococca MPI is well suited to genetic analyses because it is a heterothallic and its sexual stage can be obtained easily in laboratory conditions. Both tetrad and random ascospore analysis are possible and many traits relating to sexual reproduction, cultural appearance, heterothallism and tolerance to fungistatic compounds have been studied for this fungus through meiosis $[1,5,6]$.

In this study, the mode of inheritance of virulence in two strains of $N$. haematococca MPI against unwounded cucurbit fruits was genetically analyzed through meiosis in relation with two other traits, perithecia color and matting genes.

\section{MATERIALS AND METHODS}

Fungal strains and culture.-Two standard strains of $N$. haematococca MPI were purchased from American Type Culture Collection (www. atcc.org), ATCC18098 and ATCC18099. They were grown on potato dextrose agar (PDA) for routine use and V8-juice agar [7] was used for crossing experiments. 
Reciprocal crossing.-Reciprocal crossing between ATCC18098 and ATCC18099 was made using the modified procedure of VanEtten [8]. Conidia of each strain were separately spread on V8 juice agar in plastic Petri dishes (10-cm diameter) and mycelia were allowed to develop by incubating at $22-24{ }^{\circ} \mathrm{C}$ for $10-15$ days under continuous fluorescence lighting. For spermatization, about $10 \mathrm{~mL}$ of conidial suspension prepared from the V8-juice plate culture was poured on the mycelia of the strain acting as the female. After 5 mints, the conidial suspension was drained, and the fertilized cultures were incubated as above for 2-3 weeks to allow formation of mature perithecia.

Ascospores analysis. - In random ascospore analysis, ascospore masses oozing from mature perithecia were suspended in distilled water and spread on $4 \%$ (w/v) water gelatin plates. Single ascospores were randomly isolated using a handmade flexible glass needle and cultured on PDA slants. For tetrad analysis, mature perithecia from each cross were washed with water to remove any conidia on their surface and squashed with a pair of forceps in a drop of water on the surface of $4 \%$ water gelatin plates to release asci. The individual asci were then moved to new water gelatin plates. Ascospores were isolated from each ascus using a glass needle and cultured on PDA slants.

Virulence test.-Both parents and the selected progenies were tested for their virulence on seedlings and fruits of Cucumber (Cucumis sativus) and Zucchini (Cucurbita pepo). Stems of uniform seedlings were washed in running tap water before inoculation with 6-mm-diameter plug each of 7-11days' old mycelium culture [4]. For fruits, 3-4 mycelial agar plugs were used for each and covered with parafilm stripes, and then they were incubated at room temperature in sealed aluminum trays with moist paper. All the inoculated seedlings and fruits were placed in the glasshouse. Development of symptoms was observed every 2 days for 15 days. The experiment was repeated twice.

MAT and the perithecial color.-In both types of ascospore analyses, MAT and the perithecial color were detected to check if segrega- tion in sexual crosses was normal for the other chromosomes. Both traits were determined by back-crossing of each ascospore progenies with each parental strain.

\section{RESULTS AND DISCUSSION}

Host specificity in fungal pathogen-host interactions is of great importance for the virulence of a specific organism. Physical attachment to the host, mediated by specific binding of homologous fungal material to the cell surface $[9,10,11,12]$, and the subsequent host-parasite recognition are early stage examples of such specificity. In this study, mycelium agar plugs were used instead of conidial suspension for inoculation to confirm best contact of fungal conidia to plant surface $[13,14]$. Also, both standard strains were selected; ATCC18098 is a MAT1-1 hermaphrodite with red perithecia and ATCC18099 is a MAT1-2 hermaphrodite with white perithecia to ensure reciprocal crossing and recognizable color difference [15].

The inheritance mode of virulence in sexual crosses was studied by tetrad and random ascospore analysis with ascospores obtained from reciprocal crossings between ATCC18098 and ATCC18099. Generally, for detecting the degree of virulence of a progeny, the length and/or the diameter of infection lesions on a seedling hypocotyle and fruit exocarp were recorded. The results showed high virulence of both parental strains (Table 1) and their progenies on inoculated seedlings with no significant differences, which are in agreement with many previous works $[3,11,16,17]$.

On the other hand, both strains and their progenies have different virulence against noninjured fruits. Out of 200 random ascospores progenies were obtained from two reciprocal crosses, and while strain ATCC18099 beside 90 progenies were failed to colonize non-injured zucchini fruits, Strain ATCC18098 and the rest progenies did (Table 2), thus suggesting the heterogeneity between the two studied strains. Chi-square test supported that progenies with and without the ability to infect non-injured fruit segregated in 1:1 in each cross. Subsequently, random assortment between virulence and other chromosomes during meiosis were examined us- 
inheritance mode of virulance in Nectria haematococca Matting Population I

Table 1. Virulence of $N$. haematococca MPI on two different cucurbits.

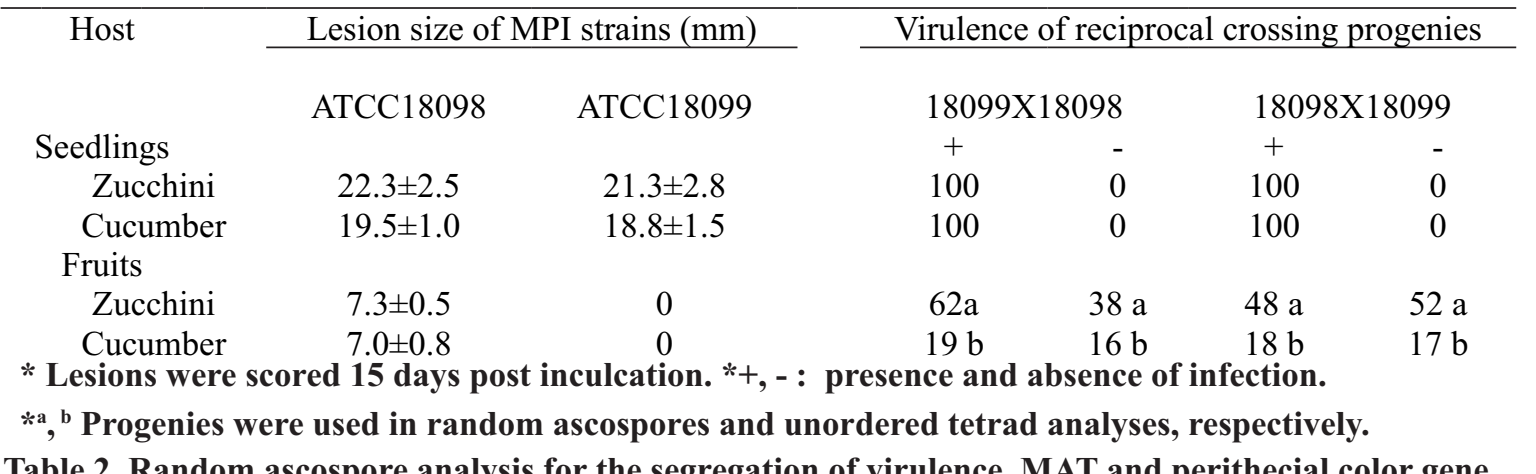

Table 2. Random ascospore analysis for the segregation of virulence, MAT and perithecial color gene.

\begin{tabular}{|c|c|c|c|}
\hline \multirow{2}{*}{$\begin{array}{c}\text { Cross } \\
(\mathrm{F} \times \mathrm{M})\end{array}$} & \multicolumn{2}{|c|}{ Segregation } & \multirow{2}{*}{ Chi-square test } \\
\hline & $+^{\mathrm{a}}$ & $-^{\mathrm{a}}$ & \\
\hline \multicolumn{4}{|c|}{ ATCC18099 × ATCC18098 } \\
\hline VR & 62 & 38 & $0.50<\mathrm{P}<0.75$ \\
\hline & MAT1-1:MAT1-2= 30:32 & $M A T 1-1: M A T 1-2=20: 18$ & $0.25<\mathrm{P}<0.50$ \\
\hline VR, PC & red:white $=32: 30$ & red:white $=13: 25$ & $0.25<\mathrm{P}<0.50$ \\
\hline $\begin{array}{l}\text { MAT1 } \\
\text { MAT1 }\end{array}$ & $\begin{array}{l}\text { T, PC } \\
\text { hite }=17: 13 \\
\text { hite }=15: 17\end{array}$ & $\begin{array}{l}\text { MAT1-1, red:white }=8: 12 \\
M A T 1-2, \text { red:white }=6: 12\end{array}$ & $0.50<\mathrm{P}<0.75$ \\
\hline \multicolumn{4}{|c|}{ ATCC18098 $\times$ ATCC18099 } \\
\hline VR & 48 & 52 & $0.75<\mathrm{P}<0.90$ \\
\hline VR, MAT & $M A T 1-1: M A T 1-2=23: 25$ & $M A T 1-1: M A T 1-2=23: 29$ & $0.50<\mathrm{P}<0.75$ \\
\hline VR, PC & red: white $=25: 23$ & red: white $=20: 32$ & $0.50<\mathrm{P}<0.75$ \\
\hline VR, MAT, PC & $\begin{array}{l}\text { MAT1-1, red: } \text { white }=13: 10 \\
\text { MAT1-2, red:white }=12: 13\end{array}$ & $\begin{array}{l}\text { MAT1-1, red: } \text { white }=10: 13 \\
M A T 1-2, \text { red: } w h i t e=10: 19\end{array}$ & $0.50<\mathrm{P}<0.75$ \\
\hline
\end{tabular}

${ }^{\text {a }}$, Fruit infected; -, Fruit not infected; VR, Virulence; PC, perithecial color.

b $M A T 1$-1,red:MAT1-1,white: MAT1-2,red:MAT1-2,white=13:10:12:13. $\mathbf{P} \chi^{\mathbf{2}}(\mathbf{1}: 1: 1: 1)$ is $>\mathbf{0 . 9}$,

' $M A T 1-1$, red:MAT1-1,white:MAT1-2,red:MAT1-2,white=10:13:10:19. $\mathbf{P} \chi^{2}(\mathbf{1 : 1 : 1 : 1 )}$ is $\mathbf{0 . 2 5}<\mathbf{P}<\mathbf{0 . 5 0}$.

ing MAT and perithecial color as markers. These two traits were independently inherited $[15,18]$. The linkage analysis of the selected ascospores showed that virulence segregates independently from either trait.

To confirm the mode of inheritance of such trait for strain ATCC18099, tetrad analysis was performed and several sets of eight ascospores were isolated from asci, but no complete tetrads (exactly, octads) were obtained due to the failure of ascospore germination.

Ideally, the eight ascospores representing mitotic pairs of the four meiotic products are recovered from each ascus to perform tetrad analysis in $N$. haematococca. Such incomplete asci were included in the analysis if genotypes of missing ascospores could be deduced to reconstruct complete tetrad based on the segregation of MAT and perithecia color genes [15]. Consequently, ten incomplete tetrads with seven germinated ascospores were subjected to analyses.
The results showed that, irrespective of whether the ascospores were transmitted from female or male, each of the reconstructed tetrads showed 4:4 segregation of virulence, suggesting Mendelian inheritance manner. The results of both MAT and perithecial color showed that segregation in sexual crosses was normal for the other chromosomes (Table 3).

So far, only a few studies have applied a genetic approach to identify virulence factors. Several cases about involvement of only a limited number of loci for virulence have been reported. In the barley pathogen Cochliobolus sativus, studies indicate a single locus controlling virulence on a particular cultivar [19] and virulence of the apple scab causing pathogen Venturia inaequalis has been shown to be controlled by a single major locus [20], that has its gene-forgene counterpart in the apple host [21]. In Phytophthora infectans, six loci were identified as possible virulence factors [22]. 
Table 3. Unordered tetrad results for the segregation of virulence towards non-injured fruits, MAT and perithecial color gene

\begin{tabular}{|c|c|c|c|c|c|c|c|c|c|c|c|c|c|c|c|c|c|c|c|}
\hline \multicolumn{10}{|c|}{ ATCC18099XATCC18098 } & \multicolumn{10}{|c|}{ ATCC18098XATCC18099 } \\
\hline \multirow{2}{*}{ Ascus } & \multirow{2}{*}{ Trait } & \multicolumn{8}{|c|}{ Ascospore } & \multirow{2}{*}{ Ascus } & \multirow{2}{*}{ Trait } & \multicolumn{8}{|c|}{ Ascospores } \\
\hline & & 1 & 2 & 3 & 4 & 5 & 6 & 7 & 8 & & & 1 & 2 & 3 & 4 & 5 & 6 & 7 & 8 \\
\hline \multirow{3}{*}{ A } & VR & - & - & - & $-^{m}$ & + & + & + & + & \multirow{3}{*}{$\mathrm{F}$} & VR & + & + & + & + & - & - & - & $-{ }^{m}$ \\
\hline & MAT & 1 & 1 & 2 & 2 & 1 & 1 & 2 & 2 & & MAT & 1 & 1 & 1 & 1 & 2 & 2 & 2 & 2 \\
\hline & $\mathrm{PC}$ & $\mathrm{W}$ & $\mathrm{W}$ & $\mathrm{R}$ & $R$ & $\mathrm{R}$ & $\mathrm{R}$ & W & $\mathrm{W}$ & & $\mathrm{PC}$ & $\mathrm{W}$ & W & $\mathrm{R}$ & $\mathrm{R}$ & $\mathrm{W}$ & W & $\mathrm{R}$ & $R$ \\
\hline \multirow{3}{*}{ B } & VR & + & + & + & + & - & - & - & $-^{m}$ & \multirow{3}{*}{ G } & VR & - & - & - & $-^{m}$ & + & + & + & + \\
\hline & MAT & 1 & 1 & 2 & 2 & 2 & 2 & 1 & 1 & & MAT & 2 & 2 & 1 & 1 & 2 & 2 & 1 & 1 \\
\hline & $\mathrm{PC}$ & $\mathrm{R}$ & $\mathrm{R}$ & $\mathrm{R}$ & $\mathrm{R}$ & W & W & W & $W$ & & $\mathrm{PC}$ & W & W & W & $W$ & $\mathrm{R}$ & $\mathrm{R}$ & $\mathrm{R}$ & $\mathrm{R}$ \\
\hline \multirow{3}{*}{$\mathrm{C}$} & VR & + & + & + & $+^{m}$ & - & - & - & - & \multirow{3}{*}{$\mathrm{H}$} & VR & + & + & + & $+^{m}$ & - & - & - & - \\
\hline & MAT & 1 & 1 & 2 & 2 & 2 & 2 & 1 & 1 & & MAT & 2 & 2 & 2 & 2 & 1 & 1 & 1 & 1 \\
\hline & $\mathrm{PC}$ & W & $\mathrm{W}$ & $\mathrm{R}$ & $R$ & W & W & $\mathrm{R}$ & $\mathrm{R}$ & & $\mathrm{PC}$ & $\mathrm{W}$ & W & $\mathrm{R}$ & $R$ & $\mathrm{R}$ & $\mathrm{R}$ & W & W \\
\hline \multirow{3}{*}{$\mathrm{D}$} & VR & + & + & + & + & - & $-^{m}$ & - & - & \multirow{3}{*}{ I } & VR & - & - & - & $-^{m}$ & + & + & + & + \\
\hline & MAT & 1 & 1 & 1 & 2 & 2 & 1 & 1 & 2 & & MAT & 2 & 2 & 2 & 2 & 1 & 1 & 1 & 1 \\
\hline & $\mathrm{PC}$ & $\mathrm{W}$ & $\mathrm{W}$ & $\mathrm{R}$ & $\mathrm{R}$ & $\mathrm{R}$ & $R$ & $\mathrm{~W}$ & $\mathrm{~W}$ & & $\mathrm{PC}$ & $\mathrm{W}$ & W & $\mathrm{R}$ & $R$ & $\mathrm{~W}$ & W & $\mathrm{R}$ & $\mathrm{R}$ \\
\hline \multirow{3}{*}{$\mathrm{E}$} & VR & + & + & + & + & - & - & - & $-{ }^{m}$ & \multirow{3}{*}{$\mathrm{J}$} & VR & + & + & + & $+^{m}$ & - & - & - & - \\
\hline & MAT & 2 & 2 & 2 & 2 & 1 & 1 & 1 & 1 & & MAT & 1 & 1 & 2 & 2 & 2 & 2 & 1 & 1 \\
\hline & $\mathrm{PC}$ & $\mathrm{R}$ & $\mathrm{R}$ & W & W & $\mathrm{R}$ & $\mathrm{R}$ & W & $W$ & & $\mathrm{PC}$ & $\mathrm{W}$ & W & $\mathrm{R}$ & $R$ & $\mathrm{R}$ & $\mathrm{R}$ & W & W \\
\hline
\end{tabular}

$\left({ }^{\mathrm{m}}\right)$ : missing ascospore progeny;,+- : presence and absence of infection 1,2 : MAT1- genes; R, W: perithecial color.

The results obtained here, the difference in virulence for the same strain on different plant tissues, support the previous report in N. haematococca MPI that several loci for pathogenicity are present [14], and also in agreement with the results obtained by analyzing a progeny population of Gibberella zeae that causes head blight of wheat which suggested that only few loci for pathogenicity and aggressiveness segregate in the progeny [23].

Moreover, results showed that virulence trait in the genome of the studied strains, unlike some reports that it is maternally inherited [3], was independently segregated and wasn't correlated with either matting or perithecia color genes.

In conclusion, this study suggests that pathogenicity in Nectria haematococca MPI is controlled by more than one locus in the genome thus the variation in virulence between the two strains and this trait is dependently inherited through meiosis. Also, virulence inheritance is not related neither to matting genes nor the perithecial color genes.

\section{RFERENCES}

[1] Snyder WC, Georgopoulos SG, Webster RK and Smith

SN. 1975. Sexuality and genetic behaviorin the fungus Hypomyces (Fusarium) solani f. sp. cucurbitae. Hilgardia 43:161-185.

[2] Tousson TA and Snyder WC. 1961. The pathogenicity, distribution, and control of two races of Fusarium (Hypomyces) solani f. cucurbitae. Phytopathology 51:17-22.

[3] Hawthorne BT, Ball RD and Rees-George J. 1994. Genetic analysis of variation of pathogenicity in Nectria haematococca (Fusarium solani) on Cucurbita sp. Mycol. Res. 98:1183-1191.

[4] Gevens AJ, Ando K, Lamour K, Grumet R and Hausbeck MK. 2006. Development of a detached cucumber fruit assay to screen for resistance and effect of fruit age on susceptibility to infection by Phytophthora capsici Plant Dis. 90:1276-1282.

[5] Georgopoulos SG. 1963. Pathogenicity of chlorinatednitrobenzene tolerant strains of Hypomyces solani $f$. cucurbitae race 1. Phytopathology 53:1081-1085.

[6] VanEtten HD and Kistler HC. 1988. Nectria haematococca mating population I and VI. In: Advances in Plant Pathology, Vol. 6. Genetics of plant pathogenic fungi. Sidhu GS, ed. Academic Press, London.

[7] Stevens RB. 1974. Mycology Guidebook. Univ. of Washington Press, Seattle.

[8] VanEtten HD. 1978. Identification of additional habitats of Nectria haematococca mating population VI. Phytopathology 68:1552-1556. 
[9] Albersheim P and Anderson-Prouty AJ. 1975. Carbohydrates, proteins, cell surface, and the biochemistry of pathogenesis. Ann. Rev. PL Physiol. 26: 31-52.

[10] Manocha MS. 1985. Specificity of mycoparasite attachment to the host cell surface. Cana. J. Bot. 63(4):772778.

[11] Jones MJ and Epstein L. 1989. Adhesion of Nectria haematococca macroconidia. Physiol. Mol. Plant Pathol. 35:453-461.

[12] Jones EBG. 1994. Fungal adhesion. Mycol Res 98: pp. 961-981.

[13] Hamer JE and Howard RJ, Chumley FG, Valent B. 1988. A mechanism for surface attachment of spores of a plant pathogenic fungus. Science 239:288-290.

[14] Hawthorne BT, Rees-George J and Crowhurst RN. 2001. Induction of cutinolytic esterase activity during saprophytic growth of cucurbit pathogens, Fusarium solani f. Sp. cucurbitae races one and two (Nectria haematococca MPI and MPV). FEMS Microbiol Lett 194:135-141.

[15] Mahmoud AM and Taga M. 2012. Cytological karyotyping and characterization of a $410 \mathrm{~kb}$ minichromosome in Necteria haematococca MPI. Mycologia 104:845-856.

[16] Jones MJ and Epstein L. 1990. Adhesion of Macroconidia to the plant surface and virulence of Nectria hae- matococca. Appl. Environ. Microbiol. 56:3772-3778.

[17] Hawthorne BT, Rees-George J and Broadhurst PG. 1992. Mating behaviour and pathogenicity of New Zealand isolates of Nectria haematococca (Fusarium solani). New Zealand J. Crop Hortic. Sci. 20:51-57.

[18] Zhon S and Steffenson BJ. 2001. Virulence and molecular diversity in Cochliobolus sativus. Phytopathology 91:469-476.

[19] Sierotzki H and Gessler C. 1998. Genetic analysis of a cross of two Venturia inaequalis strains that differ in virulence. J. Phytopathology 146(10):515-519.

[20] Vinatzer BA, Patocchi A, Gianfranceschi L, Tartarini S, Zhang HB, Gessler C and Sansavini S. 2001. Apple contains receptor-like genes homologous to the Cladosporium fulvum resistance gene family of tomato with a cluster of genes cosegregating with Vf apple scab resistance. Molecular Plant-Microbe Interactions 14(4):508515 .

[21] Jiang RH, Weide R, Van de Vondervoort PJ and Govers F. 2006. Amplification generates modular diversity at an avirulence locus in the pathogen Phytophthora. Genome Res 16:827-840.

[22] Cumagun CJR, Bowden RL, Jurgenson JE, Leslie JF and Miedaner T. 2004. Genetic mapping of pathogenicity and aggressiveness of Gibberella zeae (Fusarium graminearum) towards wheat. Phytopathology 94: 520526. 


\section{طريقة التوارث للجينات المسئولة عن الإصابة فى النكتريا هيماتوكوكا ـالمجموعة التوارثية الأولى \\ أحمد محمد محمود أحمد قاسم \\ قسم النبات و الميكروبيولوجى- كلية العلوم - جامعة الأز هربأسيوط - أسيوط - مصر امدر}

$$
\text { ملخص البحث }
$$

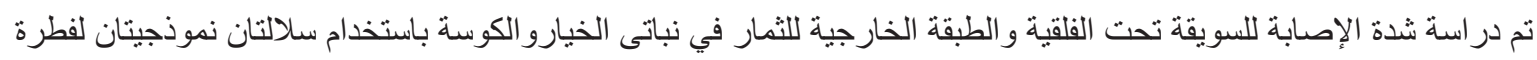

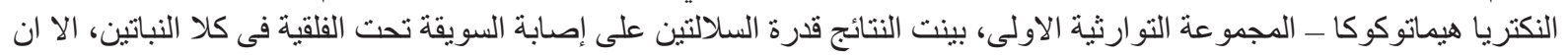
السلالة ATCC18099 اظظهرت عدم قدرتها على اصابة الطبقة الخارجية للثمار في كلا النباتين بعكس السلالة يرجح تحكم اكثر من جين فى شدة الاصنابة.

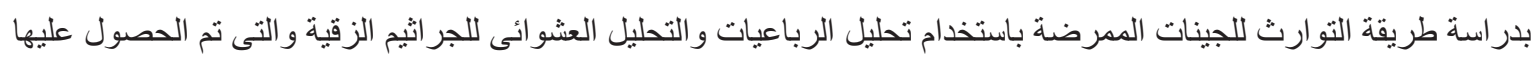

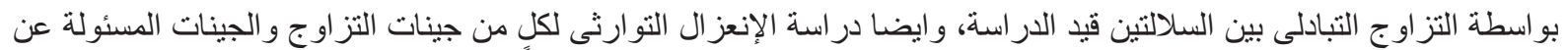

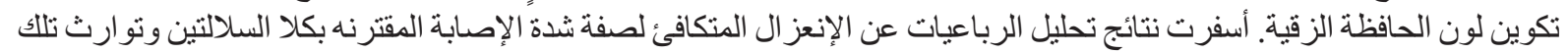

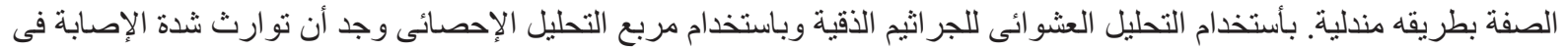

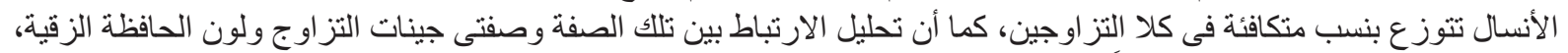

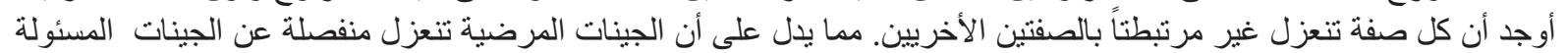
عن الصفتين الأخرتين. 